\title{
A cidade do sonho e a cidade sitiada em $A$ doce canção de Caetana, de Nélida Piñon
}

\author{
Lúcia Regina Lucas da Rosa
}

\begin{abstract}
Resumo: Este ensaio analisa a influência da cidade na trajetória da personagem Caetana do romance $A$ doce canção de Caetana, de Nélida Piñon. A personagem sai de sua pequena cidade natal em busca de sucesso como atriz e vai para a cidade grande. Decepcionada, retorna e tenta realizar seu sonho na própria de origem, o que também não consegue, pois ali se vale do teatro para transformá-la em prisioneira. Assim, vai embora novamente, deixando pra trás sonhos e amores.
\end{abstract}

\begin{abstract}
This essay analyzes the influence of the city in the trajectory of Caetana, a character of the novel $A$ doce canção de Caetana, by Nélida Piñon. The character leaves her small hometown in search of the success as an actress and moves to a big city. Disappointed, she comes back home and continues trying to make her dream come true, what she also does not achieve, since the theater makes her into a prisoner. Thus, she leaves again, leaving dreams and love behind.
\end{abstract}

A cidade exerce forte influência sobre a condição de existência das personagens do romance A doce canção de Caetana, de Nélida Piñon (Record, 1987). Assim como impulsiona a personagem principal a correr atrás do seu sonho, também a repudia, sitiando-a na irrealização deste sonho. No percurso do interior à capital, o mito de sua atuação artística permanece para si e para os seus conterrâneos. Toda a espera de sua volta enche de mistérios a pequena Trindade e também lhe dá existência pela saudade e certeza de sua volta. Conforme a própria autora, o livro trata da ilusão, que é um caráter fundamental da criação (cf. MONIZ, 1993, p. 170). A protagonista sacrifica o amor de seu amante, que lhe mantém casa e comida, e apesar de não ter como se sustentar, abandona-o mais uma vez. Pior que passar fome é não atingir o sucesso. Ela, frustrada, nunca deixa de ser uma artista mambembe.

Nesta obra, cumpre-se o mito do eterno retorno, a chegada à terra prometida, a tentativa de encontrar o paraíso, na medida em que a personagem vai a sua cidade natal para voltar às origens, visto que, sabe que lá ainda é valorizada. O paraíso passa a ser a reconstrução do passado a fim de realizar desejos do presente. O éden surge como única alternativa de organização de vida com vistas à realização pessoal. Assim, de cidade em cidade, Caetana penitencia-se por uma volta prometida, mas feita de forma avessa, ou seja, 
em vez de ter obtido a fama, volta como última tentativa de construir carreira. O mito arquetípico da terra prometida é recorrente na literatura, em obras clássicas e modernas como Canaã, de Graça Aranha; Fundador, de Nélida Piñon; Visão do paraíso, de Sérgio Buarque de Holanda; enfim, desde os textos bíblicos:

O mito de uma vida perfeita aparece em todas as civilizações, com algumas variações, mas anunciando sempre o retorno a uma situação justa. Arquetipicamente, o mito expressa renovação do desejo e da esperança teleológica de se reconstruir a utopia do espaço edênico. A narrativa mítica reproduz o caráter do discurso religioso de punição e expiação da culpa primordial que estigmatizou o homem, ou seja, a pretensão do conhecimento infinito, a posse do significado transcendental que o tornaria onisciente e igual ao Deus absoluto. Na dispersão da descendência de Adão após a perda do Jardim de Delícias, funda-se o mito da nostalgia adâmica, ou seja, o fascínio pela restauração da unidade primordial e a saudade do Paraíso perdido. A retomada do solo sagrado é um dos ícones da nostalgia adâmica, perpetuado e disseminado nas migrações do mito da Terra Prometida. (NETO, 2007, p. 628)

É este desejo adâmico que impulsiona e dá coragem de retornar à cidade natal. E, para ser bem recebida, seria importante não só chegar repentinamente, pelo contrário, mesmo avisando o dia da chegada, o impacto deveria ser imenso para que seu intento se realizasse. Ser aguardada fazia parte de um cerimonial mítico. Era necessário inserir a vida na arte dramática, a começar pela primeira aparição pública, o que Nélida Piñon descreve de modo semelhante à forma triunfal de apresentação de personagens no romance em estudo:

\footnotetext{
Ao ouvir ruídos vindos de fora, Gioconda empurrou Diana. Diana atraiu-a, porém, contra os seios miúdos, sorrindo para uma humanidade vaidosa que se precipitara em direção a Caetana, acabada de entrar.

$\mathrm{O}$ perfume que inundou as narinas de todos parecia de origem animal, uma besta de exótica beleza, prevista pela visão apocalíptica de cada membro do grupo. [...]

Balinho trazia uma tocha acesa na mão. Atento às primeiras palavras de Caetana, parecia uma espécie de Nabucodonosor que, estupefato, observava a mão anônima e sem dono imprimindo na parede de sua vida a balança e outros signos. [...]

- Sou a estrela do espetáculo e receberei os coadjuvantes aqui embaixo. É cedo ainda para compartilharmos o mesmo palco. (PIÑON, 1987, p. 301-304)
}

Tal situação também pode ser encontrada em outro romance da mesma autora, Fundador, de 1969:

As paredes enfeitadas de ramos de oliveiras. A triunfal entrada de Jerusalém. Disseram-lhe e ele nem respondeu: - Mais respeitável que a morte de um homem, é este homem viver construindo uma cidade. (PIÑON, 1969, p. 48)

No caso de A doce canção de Caetana, tal aparição é tão preparada e instaurada de forma a manter-se em suspense que o leitor só a fica conhecendo a partir da página 301, o que prova a necessidade do espetáculo, pois o romance possui 396 páginas no total. Portanto, grande parte da narrativa se dá em conjecturas da chegada da atriz na cidade, cuja população vive à sua espera.

Assim como a rua da cidade para Gogol tinha como finalidade a sociabilidade, num cenário para a fantasia das pessoas e oferecimento do conhecimento verdadeiro daquilo que 
elas são (cf. BERMAN, 2007, p. 230); para Piñon, a rua da cidade oferece a opção de revelarse autenticamente ou de inventar-se por meio da arte. Se para Gogol as pessoas passam por metamorfoses durante o dia, para Piñon, a metamorfose é o que faz a pessoa ter vida. A cidade como palco da arte se apresenta de forma ambígua: ora libertadora, ora opressora. $\mathrm{Na}$ busca de liberdade, Caetana retorna à cidade natal e o que encontra é uma nova expulsão. Ao transitar pelo mundo da realidade e pelo mundo do sonho, a cidade se mostra acolhedora no início, para depois de impossibilitar a realização artística, expulsar de vez do sonho e restaurar a realidade cruel do mundo ordenado do trabalho, da ordem e da aparente tranqüilidade. No entanto, essa não era a expectativa das personagens, que viviam endossando a ilusão:

\footnotetext{
- Melhor fazer um estilo com sua feiúra. Virar personagem. Assim todos terminarão pensando que é bonita.

- Sabe o significado do que disse, Diana? perguntou Venieris, enquanto tentava localizar o próprio rosto no canto do espelho ainda não ocupado por ninguém. - É o que chamam de estética. Não é verdade, Virgílio? Gostar do que se inventa sem saber a razão! [...]

- O que não nos falta aqui são portas. Até falsas temos! Venieris protestou. Empenhara todo seu engenho na arte de simular. Fazer os demais crerem na existência de cidades elaboradas pela imaginação. Para corroborar, aliás, a tese da ilusão e fortificá-la ao mesmo tempo. [...]

- Comecemos de uma vez. Caso contrário, nos tornaremos escravos da ilusão. [...]

- Não se acanhe nem me condene. Tudo é uma farsa. Um espinho que cada um enterrou no fundo do quintal da alma. (PIÑON, 1987, p. 300-304)
}

Perpetuando a ilusão, os antigos amigos se reencontravam assumindo tal posição. Sabiam que somente algo fora da realidade poderia justificar uma espera de vinte anos. $\mathrm{O}$ espinho da alma nada mais é que o sentimento messiânico, num misto de saudade e submissão. Diante daquela presença tão esperada, imediatamente, o ritmo de vida se altera naquela pequena cidade que, a partir dali, passa a conviver com uma grande quantidade de pessoas na iminência de conhecerem um espetáculo verdadeiro. A única personagem que não se submete a esta ilusão é Dodô, a esposa traída. Ela sempre denuncia a realidade, quebrando a expectativa de Polidoro: “- Desde quando preciso tratar Trindade como cidade grande? Daqui só vejo carros velhos, caboclos desdentados e bosta de vacas soltas." (PIÑON, 1987, p. 302)

Diante de tanta submissão, a música é o instrumento de manutenção de poder da personagem. Escondida, mascarada e, ao mesmo tempo, com poderes sobre seus admiradores da pequena cidade de Trindade, mantém a farsa sobre a sua vida e um mistério sobre suas atitudes que magnetiza a população da cidade. Caetana, há vinte anos abandonara a cidade, os amigos e o amante; agora, na sua volta, deixa todos atônitos ao trazer de volta o passado e a promessa de felicidade. Engana a todos e a si mesma, na medida em que se autoproclama atriz de sucesso:

... recorro com freqüência à mentira. Faço como todos os artistas. Não é verdade que somos mentirosos? (...) Graças à mentira acreditamos nas lembranças que já tínhamos condenado ao 
esquecimento. O que seria de nós sem o afeto da mentira, o pão da mentira? É o único calor que combate a solidão.

De fato, a mentira é a única verdade que nos interessa. O resto é grosseiro e desumano. Mesmo porque a realidade está sempre a serviço da ilusão dos miseráveis e da argúcia dos ricos. (PIÑON, 1987, p. 123 e 266).

Ao admitir-se mentirosa, Caetana cria um mundo de fantasias, e faz com que todos à sua volta participem deste mundo ilusório. Entretanto, tal mentira ou fantasia brota da necessidade de continuar viva, de saber-se participante de um grupo social, de uma cidade e de pessoas que a desejam e a aceitam como celebridade. Dessa forma, a mentira passa a ser verdadeira e ela cresce em Trindade. Buscando a si mesma, ao regressar, analisa a própria trajetória de vida: "Tudo que quero é ouvir minha própria história, contada por quem se lembre dos detalhes que já esqueci” (PIÑON, 1987, p. 257). Com poder de fascínio, submete as pessoas que nutrem sentimentos fortes em relação a ela e alimenta-se desse "pão" que dá brilho à sua vida. Silenciosa, a princípio, não revela seu intento, subjugando seus súditos à admiração e migalhas de atenção. Com isso, começa a construção de um reinado e prepara a todos para um grande espetáculo. Como se a vida ficasse em suspensão, as pessoas com quem ela se relaciona passam a viver focalizando-se em Caetana, ou melhor, vivem e convivem em função da perspectiva de interação com ela. Cria-se, então, um código de expectativa, ao sabor da insegurança, da saudade do passado e de amores não realizados. Polidoro permanece um eterno apaixonado, amante abandonado, há vinte anos sem notícias, mas na certeza de que voltariam a se encontrar e de que viveriam grandes emoções novamente. Ele tudo faz para manter o quarto de hotel do mesmo jeito que estava no tempo em que se encontravam e, segundo ele, eram muito felizes. Assim, o tempo fica estagnado, como se o tivessem congelado, aguardando novas ordens do destino. Passam a ser seres autômatos, aguardando a possibilidade de satisfazer os caprichos daquela grande personalidade que retorna. E ela, por sua vez, fica de dona da situação e explora os sentimentos alheios, revertendo ansiedades e esperanças a seu favor, ou seja, à medida que aguardam suas ordens, ficam embevecidos pelo fato de serem lembrados, mesmo que ocorram apenas fortuitos encontros, rápidos e que apenas servem para assegurar o poder exercido sobre eles.

Nesse jogo de sedução-manutenção de poder, ela encarna a figura de Maria Callas (1923-1977), cantora de ópera com incrível talento dramático e musical:

... sempre que falar da Callas, use linguagem litúrgica, como se estivesse na igreja.

Ao gesto brusco, o broche que lhe abotoava o penhoar soltou-se. Ela não notou o rego do seio exposto à cupidez de Polidoro. Prosseguia mais furiosa que nunca.

- Ela foi a única autorizada pelos deuses a visitar seus templos sem véu e com sapatos altos. Podia ser uma sacerdotisa sem lhes dever qualquer favor. Nunca houve outra garganta como a dela. Acaso quer provar que estou errada? (PIÑON, 1987, p. 288) 
No seu entender, Callas era uma deusa incontestável e era mesmo preciso que todos a respeitassem e a considerassem um talento supremo, afinal, só assim Caetana poderia imitá-la, ser digna daquela personalidade à altura do talento tão crível e sem reconhecimento.

Ao correr mundo, Caetana não obteve sucesso, visto que o circo em que atuava permaneceu no ostracismo artístico e a decadência chegou rapidamente para todos os artistas, cansados de perambular de cidade em cidade. Admiradora de Callas, anunciou seu grande espetáculo - assumiu a personalidade da cantora e passou a viver um sucesso desejado para si, porém obtido por outra. Afinal, acreditar no sucesso tornava-o realidade naquele lugar pacato e sem concorrência. E crise de identidade, ela não poderia assumir-se e retornar à cidade natal sem um grande espetáculo. Assim, no dizer de HALL (2005, p. 12-13), o sujeito pós-moderno torna-se fragmentado, composto não de uma única, mas de várias identidades, não possuindo uma identidade fixa, essencial ou permanente. Tal identidade nova, assumida de acordo com a necessidade é temporária, atende, apenas, a um apelo do momento, como resposta para uma tentativa de sair de uma crise. Se assumir-se outra foge à realidade, por outro lado, dá significado tanto à cidade do interior, quanto aos seus cidadãos, na medida em que todos aceitavam a pose de artista famosa com a qual Caetana se anunciava. Isto sem levar em conta que o espetáculo anunciado tornava-se cada vez mais um mistério, a certeza do sucesso trazido da cidade grande para o interior era tal que todos aguardavam obedientemente o grande dia da estréia. Como ninguém na cidade poderia contestá-la, visto que mal sabiam de quem se tratava, acreditaram em tudo que lhes era dito, pois o que importava mesmo era satisfazer os desejos de Caetana para que ela não fugisse novamente. Como platéia fiel, concordaram até em atuar junto com ela e, se fosse preciso, ela ensinaria a arte para quem estivesse disposto a acompanhá-la. Muitas mulheres da cidade, inclusive prostitutas, antigas companheiras, passam a sentirem-se "atrizes à beira da fama" (PIÑON, 1987, p. 233). E o processo contagiava-se entre todas, pois todas as mulheres que se diziam artistas, sentiam-se maiores do que o que realmente eram; mesmo sem reconhecimento de seus conterrâneos, acreditavam caminhar em busca do sucesso e, quem sabe até, sonhavam com a possibilidade de irem para o Rio de Janeiro - o que solidificaria o reconhecimento para um público mais qualificado. Nova resignação instaura-se na promessa de sucesso e realização artística. Enquanto desse modo permanecessem, a presença tão ansiada de Caetana era garantida entre eles. Esta garantia fazia com que se sentissem menos interioranos, era a união da capital com o interior. A cidade crescia, desta forma, pois possuía uma grande artista que faria um grande espetáculo, anunciado com antecedência para que pudesse ser amplamente aguardado. 
A cantora Maria Callas, assim como Caetana, regressou à sua cidade natal, Londres, depois de algum tempo em que viveu em outros países, pretendendo atingir o sucesso, o que não ocorreu durante dois anos. Caetana retorna e é recebida com pompas de rainha, disputada e apreciada por todos, planeja a sua consagração na arte e avisa que vai realizar um grande espetáculo na cidade. Todas as atenções, então, se voltam ainda mais para ela, iniciando um mistério sobre como seria o grande show, mistério este que se manteve até o dia da grande apresentação. Parte do pressuposto de que “... uma única noite de sucesso resgata o fracasso de uma vida" (PIÑON, 1987, p. 284). Após muitas insistências, ela revela o estilo de show a se realizar com uma peça musical. Não se trata de imitação, e sim de algo mais profundo: Caetana queria transformar-se em Maria Callas e acreditava que isto seria possível, pois julgava-se superior a todos, afinal " tudo é uma farsa. Um espinho que cada um enterrou no fundo do quintal da alma" (PIÑON, 1987, p. 304). É a identidade nova se consagrando pelo poder da cidade, que lhe dá crédito e permite a manutenção da farsa. A cidade precisa de seus heróis e artistas famosos para também ser reconhecida. Da necessidade de se fazer marcar pela turnê na cidade grande, os personagens assumem novos papéis sociais. Trata-se de um dos papéis da cidade diante da modernidade, tal como afirma Octavio Ianni:

Simultaneamente, a grande cidade tem sido e continua a ser cada vez mais um laboratório excepcional. Praticamente tudo o que diz respeito à sociedade, seja esta nacional ou mundial, aí se experimenta, realiza ou frustra. Aí se imaginam, concretizam ou evaporam idéias de todos os tipos, sobre os mais diferentes aspectos da vida social. São correntes de pensamento políticas, artísticas, científicas, filosóficas e religiosas, entre outras, que emergem e propagam, ou experimentam-se e frustram-se, no jogo das forças sociais. A cidade está sempre relacionada à civilização. É na cidade que se polarizam e decantam muitas das realizações de uns e outros, indivíduos e coletividades, nações e nacionalidades, gregos e troianos, civilizados e bárbaros.

A grande cidade é sempre um vasto laboratório de experimentos e exercícios, realizações e ilusões, se focalizamos as artes, as ciências e a filosofia. Aí se cria o clima de isenção e liberdade, tanto quanto de compromisso e gratuidade, no qual podem florescer as mensagens da modernidade e os desafios da pós-modernidade. (IANNI, 2003, p. 124 e 131)

Para dar este passo rumo à experimentação de formas de vida, Caetana, integrante de um circo, rodeada de artistas em convivência diária, imagina encontrar projeção ao percorrer a cidade grande do Rio de Janeiro. Surge aí o seu laboratório experimental, na liberdade de ser o que quiser ser, na multiplicidade de identidades e tentativas diversificadas. É na cidade que a personagem tenta encontrar seu eu pleno de sucesso e a magia de tornar-se conhecida, famosa mundialmente. Tanto que, ao retornar a Trindade o faz de forma desafiadora: ela anuncia-se e faz-se ser aguardada, ela seria o próprio espetáculo, sua presença é o que há de mais esplendoroso. Tudo o que não foi possível na capital, ela espera encontrar na sua pequena cidade natal. Para tanto, escolhe a música como arte-símbolo de seu projeto. A música transformara-a em um fetiche tanto para ela mesma quanto para o povo de Trindade. 
Este aspecto foi tratado por Adorno ao fazer a diferenciação entre música de entretenimento e música de espetáculo:

Para quem a música de entretenimento serve ainda como entretenimento? Ao invés de entreter,
parece que tal música contribui ainda mais para o emudecimento dos homens, para a morte da
linguagem como expressão, para a incapacidade de comunicação. A música de entretenimento
preenche os vazios do silêncio que se instalam entre as pessoas deformadas pelo medo, pelo
cansaço e pela docilidade de escravos sem exigências. Assume ela em toda parte, e sem que se
perceba, o trágico papel que lhe competia ao tempo e na situação específica do cinema mudo.
[...] Se ninguém mais é capaz de falar realmente, é óbvio também que já ninguém é capaz de
ouvir. (ADORNO, 2005, p. 67)

Eis aqui a questão central em que a personagem se encontra: ser ela mesma o espetáculo. A música fala por ela e ambas fundem-se numa só arte. Porém, para as outras pessoas, a música cumpre o papel de entretenimento apenas, massificados pela falta de sensibilidade e de audição de si mesmos, anulados pela ausência de Caetana, fecham-se a maiores entendimentos e ficam mudos para indagações. É a afirmação do nome e não apenas o nome de uma mulher, mas de uma artista que veio da cidade grande. Portanto, não é preciso provar a capacidade artística, a cidade pequena já provou que quer absorver algo da cidade grande, quer aplaudir uma artista e não um talento, é a figura representativa da urbanidade que se move. A "docilidade de escravos" dita por Adorno vai ao encontro do título do romance: é uma doce canção. Esta adjetivação tem caráter ambíguo. O “doce” significa infantilidade, puerilidade de sentimentos, como também revela a doçura do encantamento. A música para os admiradores daquela artista é desprovida de significados, ela acontece como massificação e chega da mesma forma para todos. Tanto isto ocorre que todos ficam à mercê de Caetana, aguardando que ela determine até mesmo momentos de visita, de diálogo e definição dos papéis de cada um na apresentação e em sua vida. Não há protestos, todos se resignam e ficam até felizes em prol do bem maior: a volta de uma pessoa tão esperada e desejada. Trindade é a oportunidade de assistirem a um espetáculo de uma grande atriz, segundo ela própria se autointitulava. Novamente, vemos a presença de Callas colocada em um altar para ser idolatrada e tendo seu comportamento adotado. Não raras vezes, Maria Callas fez fama por irritar-se com empresários e até mesmo por dividir os palcos com outras cantoras líricas, como foi o caso ocorrido no Brasil, em 1951, ocasião em que fez escândalo por ser homenageada em um restaurante juntamente com Renata Tebaldi. Não admitia dividir o estrelato, nem ficar na obscuridade (cf. RIBEIRO, 2007, p. 111-113).

A música-espetáculo, erudita, que encantou Caetana, enfeitiça as pessoas a ponto de acreditarem na farsa que ela monta. O grande espetáculo que é preparado sob sigilo, revela a face verdadeira da vida. Ao revelar que a apresentação seria uma ópera, a ignorância também se revela. Ninguém sabia do que se tratava e sequer sabiam o que era uma ópera. Ela, 
sabiamente, afirma ser "um mistério", cujos instrumentos seriam "os querubins e a voz de Deus", apenas a estréia revelaria o grande espetáculo. Consumidores de arte que eram as pessoas da cidade, não questionaram muito acerca do espetáculo - eles não sabiam a dimensão de significado e diferenciação de entretenimento para espetáculo. Para a atriz, "a arte abençoa" e isto lhe basta viver.

Espetáculo à parte, Polidoro, como um autêntico vassalo, declara seu amor e dedicação: “- Se não está feliz, eis-me aqui para servi-la” (PIÑON, 1987, p. 307). Ele faz todo o jogo da obediência, acredita ter de volta seu grande amor e não poupa esforços nem dinheiro para mantê-la e fazê-la feliz. Porém, Caetana acaba decepcionando e todos na cidade ficam revoltados, querendo que o espetáculo se realize de qualquer maneira. A fúria cai sobre ela ao perceberem que foram enganados e que a grande cidade não lhes enviara um grande sucesso e sim uma pessoa mentirosa e que, talvez, nem ligasse para o povo mais simples, que vive no interior. Instaurado o conflito e jogo de poder, resolve ocupar o seu espaço. Já que a pequena Trindade não a aceitava, impõe-se a ela pelo grito, rompendo o silêncio da ausência do diálogo quando chegara. E, ao pisar no palco, começa a discursar: "- Não sabe que, sem ter um inimigo à espreita, o espetáculo não consegue imitar a vida? [...] De agora em diante, permaneceremos no Íris, como se fosse uma cidade sitiada por inimigos que não deixam passar água e comida." (PIÑON, 1987, p. 313) A partir da interdição do teatro, por vingança da esposa de Polidoro, Caetana cresceu em sua interpretação. Julgando-se vítima e perseguida por ser artista, declara guerra à cidade e enclausura-se no teatro. Consagra-se, assim, o drama da vida e da ficção. O imaginativo e o imaginário entram em choque, de acordo com Northrop Frye, acerca do ambiente do homem:

Há o mundo que ele vê e o mundo que ele constrói, o mundo em que vive e o mundo em que quer viver. Em relação ao mundo que ele vê, ou meio ambiente, a atitude essencial de sua mente é a do reconhecimento, a habilidade de ver as coisas como elas são, a compreensão clara do que é, enquanto distinto daquilo que gostaríamos que fosse. [...] A outra atitude é geralmente descrita como "criativa", uma metáfora um tanto vaga de origem religiosa, ou como imaginativa. Essa é a visão não do que é, mas do que, de outra maneira, poderia ser feito com uma dada situação. Junto com o mundo dado, está ou pode estar presente um modelo invisível de algo não-existente, mas possível e desejável. A imaginação existe em todas as áreas da atividade humana, mas em três ela tem importância particular: nas artes, no amor e na religião. (FRYE, 1999, p. 167)

É assim que Caetana resolve viver, de acordo com sua imaginação. Para tanto, nada mais autêntico que passar a viver no palco. Aí, então, a vida e a arte confundem-se e o seu sonho, impossível de se realizar no curso normal da vida, começa a ganhar espaço definido, mesmo que, para isso, tenha que ficar aprisionada. E, como a sua vida não tem mais sentido real, a fantasia e a imaginação preenchem sua existência. A vida passa a resumir-se a um teatro velho e decadente. O palco vira cenário da realidade. A cidade se fecha totalmente para 
ela e sua arte, é preciso criar uma micro-cidade só para si mesma e os outros artistas que ainda a acompanham, " acontece que cada um inventa a sua cidade, como refúgio e evasão. Não cabe mais viver apenas a realidade, ou buscar principalmente a emancipação" (IANNI, 2003, p. 137). Tudo se prepara, então, para o grande momento da apresentação. Trava-se uma discussão entre Caetana e Polidoro, que tenta trazê-la para a realidade:

- Pare, Caetana. Saia do palco! Volte para a vida [...] basta de confundir os cenários.

- A ilusão é minha sina. Estou condenada a julgar a vida sem passar recibo de quitação. Esta merda de vida não me pega mais desprevenida. [...] - Nas minhas veias corre o desmando da arte. De que me vale o amor ou a carne, se a alma é imortal? E a alma é o palco! É o sucesso! (PIÑON, 1987, p. 328-9)

É assim que o romance se encaminha para o desfecho. Fora de si, e alheia à razão, Caetana passa a viver só de apresentação, é o espetáculo que toma o lugar da vida. Ela, finalmente, vai realizar o seu grande sonho: vai ser Maria Callas, vai cantar uma ópera perante uma platéia. Veste a máscara da ficção e sente que a vida lhe acontece, "a vida para ela, só cabia no palco" (PIÑON, 1987, p. 331). O palácio virou pesadelo: "para os homens modernos, pode ser uma aventura criativa construir um palácio, e no entanto ter de morar nele pode virar um pesadelo" (BERMAN, 2007, p. 14); o sonho se desfez e a cidade retorna à sua rotina. A realização do sonho não é possível: nem o sonho de Caetana em ser atriz de sucesso, nem o de Polidoro, que queria ter sua amada de volta.

Porém o espetáculo não se efetiva. A farsa se desfaz durante a apresentação, a vitrola estraga - vingança da esposa traída - e tudo desaba. Caetana reconhece-se farsante, revela que estava dando voz aos mortos. Tudo retorna como estava antes, ela sai da cidade e promete voltar, passados mais vinte anos. Só lhe resta voltar a ser ela mesma, e todos retornam à sua vida habitual. O fetiche da música e da mulher encantada fica só na memória de alguns poucos e a vida segue seu rumo. A arte não lhe rende felicidade, ela não conseguiu se vender, não ocorreu a realização do mercado, a atriz de sucesso ficou no sonho, junto da cidade grande. No microcosmo, resta-lhe a aprendizagem do valor da mercadoria. Fazer arte também implica saber vender sua arte. Na briga da arte e da mercadoria está a possibilidade de permanência na cidade:

À medida que o ser humano, enquanto força de trabalho, é mercadoria, não tem, todavia, a necessidade de ele mesmo se transpor na mercadoria. Quanto mais ele estiver consciente desse modo de ser como algo que lhe é imposto pelo vigente sistema de produção - quanto mais ele se proletariza -, tanto mais o invade o calafrio da economia de mercado, tanto menos ele estará em condições de sentir empatia pela mercadoria. (BENJAMIN, 1985, p. 85)

A fuga para um local onde realizaria seu grande sonho, aprisiona-a na impossibilidade de ser aquela que ela gostaria de ser. Ela foge, então, mais uma vez, é expulsa, banida da vida artística, sem poder realizar-se. A cidade não perdoa aos perdedores, ou se vence nela ou se é 
vencido por ela. A arte que não se vende, que não se faz mercadoria não tem espaço na cidade. Ela está na contramão do flâneur de Walter Benjamin, que anda pela cidade, seja como trapeiro, seja como colecionador ou como boêmio, uma vez que participa do ângulo dos de baixo (cf. BOLLE, 2000, p. 396); não consegue realizar a sua arte. E nada fica, e a expulsão da cidade é impiedosa.

\section{Referências}

ARANTES, Paulo Eduardo. Adorno. São Paulo: Nova Cultural, 2005.

BERMAN, Marshall. Tudo que é sólido desmancha no ar: a aventura da modernidade. São Paulo: Companhia de Bolso, 2007.

BERND, Zilá (org.). Dicionário de figuras e mitos literários das Américas. Porto Alegre: Tomo Editorial/Editora da Universidade, 2007.

BOLLE, Willi. Fisiognomia da metrópole moderna. 2 ed. São Paulo: Editora da universidade de São Paulo, 2000.

FRYE, Northrop. Fábulas de identidade - estudos de mitologia poética. Tradução de Sandra Vasconcelos. São Paulo: Nova Alexandria, 2000.

HALL, Stuart. A identidade cultural na pós-modernidade. Tradução de Tomaz Tadeu da Silva e Guacira Lopes Louro. 10 ed. Rio de Janeiro: DP\&A, 2005.

IANNI, Octavio. Enigmas da modernidade-mundo. 3 ed. Rio de janeiro: Civilização Brasileira, 2003.

KOTHE, Flávio (org.). Walter Benjamin. São Paulo: Ática, 1985.

MONIZ, Naomi Hoki. As viagens de Nélida, a escritora. Campinas, São Paulo: Editora da Unicamp, 1993.

PIÑON, Nélida. A doce canção de Caetana. Rio de Janeiro: Record, 1987. Fundador. Rio de Janeiro: Record, 1969.

RIBEIRO, Teté. Divas abandonadas - os amores e os sofrimentos das 7 maiores divas do século XX. São Paulo: jaboticaba, 2007. Disponível em <www.lovemail.pt/callas/index.> Acesso em 28-03-2007, às 15h. 